\title{
PALABRAS DEL RECTOR
}

1 tiempo es un enigma que solo Dios puede descifrar; pasa más rápido de lo que uno

$\checkmark$ desea y más lento de lo que uno teme. Como son los hombres son los tiempos. Antes

se afirmaba que "el tiempo es oro"; ahora hay que decir que "el tiempo es hombre"

La referencia al tiempo viene a colación porque con esta edición de la revista $L E X$, se está llegando al número 9, y, como se ha planificado, a fines de año, aparecerá el número 10. Es decir, se trata de una década de publicaciones, de las que, si se realizara un balance de los contenidos, se podría colegir la riqueza de argumentos, la mayoría de los cuales han esgrimido enfoques sustanciosos sobre las diferentes áreas de la nutrida realidad jurídica, de sus implicancias, antecedentes, proyecciones, y sobre todo, de su problematicidad, que cada vez resulta más enjundiosa y exigente.

Sin embargo, la reseña de los contenidos resultaría insuficiente si no destacamos la labor de los autores, vale decir, del pensamiento creativo de quienes, con aguda y fina especulación, supieron dar forma y figura a lo que querían expresar. Sería largo impracticable citar a tan distinguidas personalidades; por ello, solo hacemos referencia de ellas precisando que todas sus ideas han quedado perennizadas en cada una de las nueve ediciones de nuestra revista.

En esta edición, como se podrá observar, se ha conjugado la presencia de autores nacionales con internacionales, incidiendo en diferentes temas, todos de exigencia actualizada, pero exaltando la misma perspectiva jurídica.

Además, en este número se incluyen trabajos de investigación científica, en los que nuestra Universidad se ha empeñado ardorosamente porque una de sus funciones principales es precisamente la especialidad científica, cumpliendo así con el aporte del conocimiento, que la universidad propone con mayor énfasis, puesto que constituye un insumo sin el cual el desarrollo del país no sería factible. La mejor definición de desarrollo es la que sostiene que sin la aplicación del conocimiento, no puede haber solución de los problemas. Ciertamente, sin desarrollo no hay progreso.

En esa virtud, resulta plausible comprobar la inquietud no solo de profesores, sino también de estudiantes, lo que prueba la solidez de la nueva generación por tratar la problemática que preocupa e interesa a la mayoría de personas de nuestro país. 
Como es sabido, la ciencia y, por ende, la tecnología han cambiado la faz del mundo; han variado las relaciones sociales, familiares, económicas, laborales, deportivas, e incluso las referidas a las diversiones. Tales cambios no solo han variado las normas inherentes a la vida misma, sino que han incidido, como tenía que ser, en el campo jurídico, iniciando la necesidad de cambiar las normas o la legislación respectiva. Incluso la delincuencia, los atentados, los asesinatos, la violencia, etc., por su lado, también han adquirido visos de mayor gravedad, configurando una sociedad sin garantías.

Los delitos tienen otra configuración, y, lógicamente, el Estado y el Gobierno tienen que afrontar la situación, a fin de garantizar la seguridad y la paz. Todo esto habrá de ser estudiado y analizado científicamente por profesores y estudiantes, con el propósito de que la Facultad de Derecho haga sentir su presencia positiva para contribuir con eficacia a la creación de una sociedad para la vida.

Para terminar, habría que referir las numerosas apologías escritas como elogio de libros, revistas y todo tipo de publicaciones. Lo real es que en todo medio de comunicación resplandece la huella del hombre; el tiempo se detiene y la historia lo remoza.

Dr. Fidel Ramírez Prado, Ph.D.

Rector 